\title{
OPERATIONAL RESULTS OF THE SPALLATION NEUTORN SOURCE (SNS) POLYPHASE CONVERTER-MODULATOR FOR THE 140 KV KLYSTRON RF SYSTEM*
}

\author{
W.A. Reass, J.D. Doss, R.F. Gribble, M.T. Lynch, D.E Rees, P.J. Tallerico and D.L. Borovina \\ Los Alamos National Laboratory, P.O. Box 1663, Los Alamos, NM 87545, USA
}

\begin{abstract}
This paper describes the first operational results of the $140 \mathrm{kV}, 1 \mathrm{MW}$ average, $11 \mathrm{MW}$ peak, zero-voltageswitching, $20 \mathrm{kHz}$ polyphase bridge, boost convertermodulator for klystron pulse application. The DC-DC converter derives the buss voltages from a standard 13.8 $\mathrm{kV}$ to $2100 \mathrm{Y}$ substation cast-core transformer. Energy storage and filtering is provided by self-clearing metallized hazy polypropylene traction capacitors. Three "H-Bridge" Insulated Gate Bipolar Transistor (IGBT) switching networks are used to generate the polyphase 20 $\mathrm{kHz}$ transformer primary drive waveforms. The $20 \mathrm{kHz}$ drive waveforms are chirped the appropriate duration to generate the desired klystron pulse width. Pulse-Width Modulation (PWM) of the individual $20 \mathrm{kHz}$ pulses is utilized to provide regulated output waveforms with adaptive feedforward and feedback techniques. The boost transformer design utilizes amorphous nanocrystalline material that provides the required low core loss at design flux levels and switching frequencies. Resonant shunt peaking is used on the transformer secondary to boost output voltage and resonate transformer leakage inductance. With the appropriate transformer leakage inductance and peaking capacitance, zero-voltageswitching of the IGBT's is attained, minimizing switching losses. Reviews of these design parameters and an examination of the first operational results will be performed.
\end{abstract}

\section{INTRODUCTION}

The simplified block diagram of the convertermodulator system is shown in Figure 1. This system minimizes costs with the utilization of many standard and proven industrial and utility components.

\subsection{Component Descriptions}

The substation is a standard 3 phase $13.8 \mathrm{kV}$ to $2100 \mathrm{~V}$ vacuum-cast core transformer with passive harmonic traps and input harmonic chokes. These components are located in an outdoor rated NEMA 3R enclosure that does not require secondary oil containment or related fire suppression equipment. The Los Alamos prototype is manufactured by Dynapower Corporation in Burlington, Vermont. The substation is followed by an SCR preregulator that accommodates incoming line voltage variations and other voltage changes resulting from transformer and trap impedances, from no-load to fullload. The SCR pre-regulator also provides the soft-start function. The SCR pre-regulator provides a nominal +/1250 Volt output to the energy storage capacitor banks. The SCR pre-regulator utilized in the Los Alamos prototype is manufactured by $N W L$ in Bordentown, New Jersey. The energy storage uses self-clearing capacitors developed for the traction industry. As in traction application, these capacitors are hard bussed in parallel. These capacitors do not fail short, but, based on the use of metallized hazy polypropylene, they fuse or "clear" any internal anomaly. At our capacitor voltage rating $(1.5 \mathrm{kV})$ there has not been a recorded internal capacitor buss failure. In this application, as in traction motor applications, the capacitor lifetime is calculated to be 400,000 hours, including derating factors. A special low inductance design for these capacitors has been developed by Thomson Components in Saint-Apollinaire, France. The Insulated Gate Bipolar Transistors (IGBT's) are configured into three " $\mathrm{H}$ " bridge circuits to generate a three phase $20 \mathrm{kHz}$ square wave voltage drive waveform applied to the transformer primaries. The IGBT's are

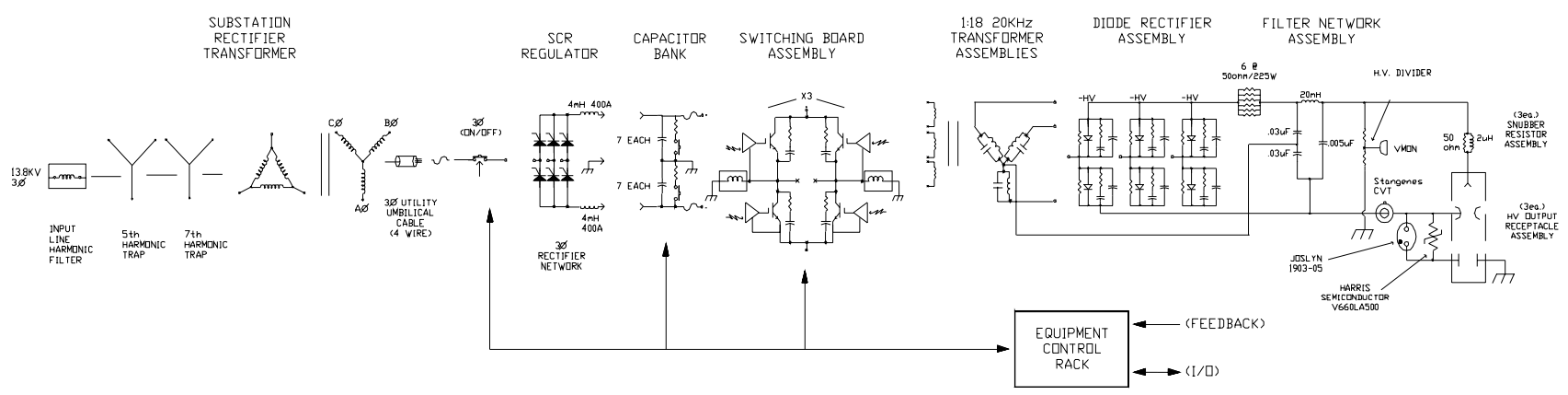

Figure 1: Simplified Block Diagram

*Work supported by the Office of Basic Energy Science, Office of Science of the US Department of Energy, and by Oak Ridge National Laboratory 
"chirped" the appropriate duration to generate the high voltage klystron pulse, typically $1.2 \mathrm{~ms}$. Due to the IGBT switching power levels, currents, and frequencies involved, low inductance busswork and bypassing is of paramount importance. The IGBT's are 3300 volt, 1200 amp devices manufactured by EUPEC of Hanau, Germany. The boost transformers utilize amorphous nanocrystalline material that has very low loss at the applied frequency and flux swing. Operating at $20 \mathrm{kHz}$ and about 1.6 Tesla bi-directional, the core loss is about 1.2 watts per pound in our application, or $320 \mathrm{~W}$ per core. Each of the "C" cores (one for each phase) weigh $260 \mathrm{lbs}$. and has a 3.5 " by 5" post. The output high-voltage rectification circuit is a standard six-pulse rectification circuit with a "pi-R" type filter network. The diodes are high-voltage fast recovery ion-implanted types, manufactured by IXYS, which are series connected with the appropriate compensation networks. The diodes have the second highest total power loss (after the IGBT's) and are oil cooled.

\subsection{Special Features of the Transformer and IGBT Design}

By appropriately spacing the secondary from the primary, the transformer leakage inductance can be resonated with secondary shunt peaking capacitors to maximize voltage output and tune the IGBT switch current to provide "zero-voltage-switching" with IGBT turn-on. The zero-voltage-switching occurs when the IGBT gate drive is positive, but reverse transformer primary circulating current is being carried by the IGBT internal freewheel diode. We have tuned for about $2.5 \mu \mathrm{s}$ of freewheel current before the IGBT conducts in the normal quadrant. This tuning provides for about $10 \%$ control range $(2.5 / 25 \mu \mathrm{s})$ for IGBT PWM. Further transformer design optimizations can change IGBT commutation (turn-off) current for control range and coupling coefficient for IGBT peak current. As transformer design characteristics interact with other circuit parameters, optimization may be performed for various klystron loads and voltages.

\subsection{Output Level Control}

IGBT PWM of the active klystron voltage pulse enables us to use feedback and adaptive feedforward techniques with digital signal processors (DSP's) to regulate and provide "flat" klystron voltage pulses, irrespective of capacitor bank "start" voltage and related droop. The DSP adaptive feedforward/feedback processor used in the Los Alamos prototype was manufactured by Z-TEC Inc., of Albuquerque, New Mexico.

\subsection{Fault Protection}

The filter network must attenuate the $120 \mathrm{kHz}$ switching ripple and have a minimal stored energy. The stored energy is wasted energy that must be dissipated by the klystron at the end of each pulse. With the parameters we have chosen, the ripple is very low ( 150 volts) and the klystron fault energy (in an arc-down) is about 10 joules. Even if the IGBT's are not turned off, the transformer resonance is out of tune in a fault condition, and little difference in klystron fault energy will result. If the IGBT's fail short, through the transformer primary winding, the boost transformer will saturate in about 30 uS, also limiting any destructive faults to the klystron. In a faulted condition, the klystron peak fault current is about twice nominal, with low dI/dT's.

\section{MODELING}

The complete electrical system of the converter/modulator system has been modeled in extreme detail. This includes design studies of the utility characteristics, transformer and rectification methodology (e.g. 6 pulse vs. 12 pulse), IGBT switching losses, boost transformer parameters, failure modes, fault analysis, and system efficiencies. Various codes such as SCEPTRE, MicrocapIV, Flux2D, and Flux3D have been used to perform these tasks. SCEPTRE has been primarily used to examine IGBT and boost transformer performance in great detail to understand design parameters such as switching losses, IGBT commutation $\mathrm{dI} / \mathrm{dT}$, buss inductance, buss transients, core flux, core flux offset, and transformer Eigen frequencies. Flux2D and Flux3D have been used to examine transformer coupling coefficients, leakage inductance, core internal and external flux lines, winding electric field potentials, and winding field stresses. The Flux2D and Flux3D were particularly useful to examine transformer secondary winding profiles that gave the desired coupling coefficients with minimized electrical field stresses. Micro-CapIV has been used to examine overall design performance of the system. This includes the utility grid parameters such as power factor, line harmonics, and flicker. We have optimized the design to accommodate the IEEE-519 and IEEE-141 harmonic content and flicker standards. Comparisons between the SCEPTRE and MicrocapIV codes show no significant differences in the system operational performance such as switching currents, switching voltages, and output voltage.

\section{FIRST RESULTS}

The converter-modulator made its first high voltage pulse on January 17, 2001. After 10 days of testing and replacement of defective dummy load components, full pulse output voltage $(140 \mathrm{kV})$, pulse width $(\sim 1.2 \mathrm{~ms})$, and peak power (11 MW) were obtained. As shown in Figure 2 , the $140 \mathrm{kV}$ risetime is about $20 \mu \mathrm{s}$ with about a $6 \%$ bank droop. The risetime compares favorably to other long-pulse modulator topologies.

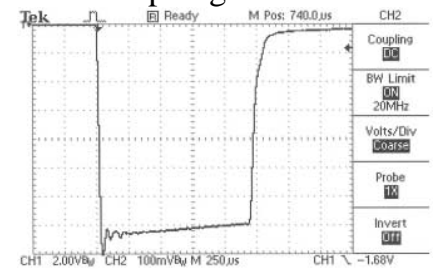

Figure 2: $140 \mathrm{kV}$ Output Pulse, $20 \mathrm{kV/Division}$ 
Additional high-voltage tests were made at $80 \mathrm{kV}$, as this voltage will be used in the SNS linac superconducting portion. The $80 \mathrm{kV}$ operations are shown in Figure 3. 80 $\mathrm{kV}$ operations with the DSP adaptive feedforward/feedback processor is shown in Figure 4. The DSP processor removes all overshoot and bank voltage droop. Extensive fault testing has also been performed with three times the anticipated high-voltage cable length as will be used in SNS

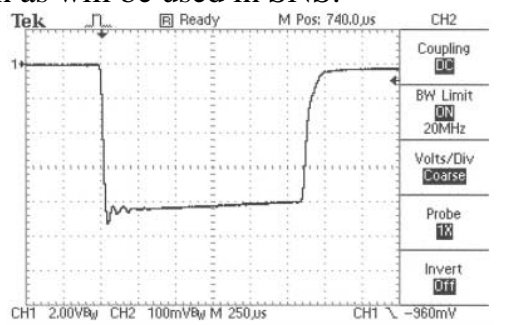

Figure 3: $80 \mathrm{kV}$ Output Pulse, $20 \mathrm{kV} /$ Division

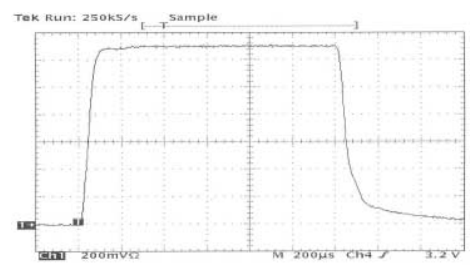

Figure 4: $80 \mathrm{kV}$ Output with Adaptive Feedforward/Feedback

The most severe crowbar test is the event of when the klystron arcs, but the converter-modulator continues switching the duration of the fault, causing a "run-on" fault situation. Modeling of this result shows a slight increase in klystron fault energy (to about 10 Joules) and a slight increase in IGBT current. The results of these tests are shown in Figure 5 and 6. Figure 5 shows a 130 $\mathrm{kV}$ crowbar test with the IGBT switch drive immediately terminated at the fault event. Figure 6 shows the same test, but the IGBT switching is not inhibited. The surprising result was that the IGBT over-current monitors additionally did not trip. The low primary IGBT driving voltage cannot significantly increase primary IGBT current because the high transformer winding reactance cannot drive higher currents from the shorted and now deQed (resonant tuned) secondary winding. These results match our computer modeling very accurately.

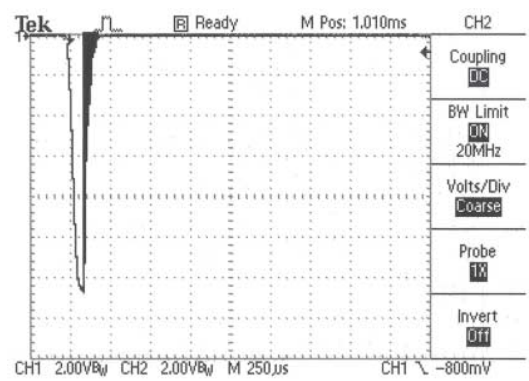

Figure 5: $130 \mathrm{kV}$ Self-Break Crowbar Test

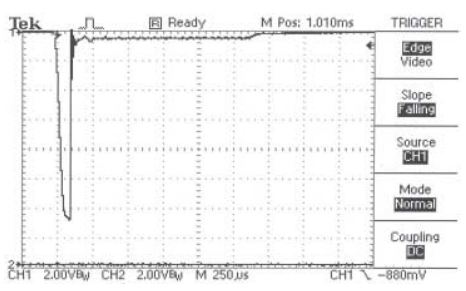

Figure 6: 130 kV Run-On Fault Test

\section{PROJECT STATUS}

The low average power testing of the first article has been completely successful. The substation construction work is completed and high average power testing has begun in May. We are presently testing on a $250 \mathrm{~kW} 402$ $\mathrm{MHz}$ klystron. Continued testing to the advertised 1 Megawatt average power is of high importance. Testing at these power levels will commence once facility upgrades (such as cooling water) and loads (klystrons) become available.

\section{CONCLUSION}

The converter-modulator has demonstrated several new design methodologies that are expected to revolutionize long-pulse klystron modulator design. These items include special low-inductance self-clearing capacitors, large amorphous nanocrystalline cut-core transformers, high-voltage and high-power polyphase quasi-resonant DC-DC conversion, and adaptive power supply control techniques. The first test results on the initial design were achieved in about a year after conception. Design economies are achieved by the use of industrial traction motor components (IGBT's and self-clearing capacitors) and standard utility cast-core power transformers. The compact and modular design minimizes on-site construction and a simplified utility interconnection scheme further reduces installation costs. The design does not require capacitor rooms and related crowbars. By generating high-voltage only when needed, reliability and personnel safety is greatly enhanced. This approach provides design flexibility to operate klystrons of different voltages primarily by changing the boost transformer turns ratio. Other optimizations also permit " $\mathrm{CW}$ " operation of the polyphase boost converter topology. All testing of the full-scale system have been completely successful and all results agree with modeling efforts to date, which indicate the design methodologies will be imminently successful.

\section{ACKNOWLEGMENTS}

The authors would like to especially thank the talented contributions and efforts of David Baca, David Miera, Jeff Griego, Gabriel Roybal, Chris Roybal, Marvin Roybal, Sean Apgar, Jacqueline Gonzales, and Pete Trujillo. Industrial consultations have been very fruitful with help and guidance from Jan Przybyla of Marconi in Chelmsford, England and George Schoefield of Maxwell Systems Group in San Diego, California. 